\title{
Hubungan Antara Kontrol Diri dengan Teamwork pada Pemain Futsal Usia Dewasa Awal di Jakarta Timur
}

\author{
Misbah Mukrom ${ }^{1}$, Sri Mulyani Nasution ${ }^{2, *)}$, Erry Indriani $^{3}$ \\ Fakultas Psikologi Universitas Jayabaya
}

*) Corresponding author: riri.nasution@ymail.com

\begin{abstract}
Early adulthood is a period of adjustment to new life patterns and new social expectations. In early adult futsal players, individuals often experience emotional tension. When futsal players experience emotional tension, most of them cannot control themselves. Self-control is an attempt to override or inhibit automatic reactions, habits, or behaviors that are brought from childhood, insistence, emotions, or desires that can interfere with achieving the main goal. This means that individuals are less able to control themselves during futsal matches. While teamwork is a form of group work with complementary skills when committed to achieving common goals effectively and efficiently. This study aims to determine the relationship between self-control and teamwork in early adult futsal players in East Jakarta. Research subjects were 110 people using accidental sampling. The method of analyzing data uses the statistical correlation test method, namely product moment correlation. Based on the analysis of the data it was found that there was a significant relationship between self-control and teamwork in early adult futsal players in East Jakarta. This can be seen from the acquisition of the correlation coefficient of 0.187 with a significance level of 0.01 .
\end{abstract}

\begin{abstract}
Abstrak
Usia dewasa awal adalah periode penyesuaian diri terhadap pola-pola kehidupan baru dan harapanharapan sosial baru. Pada pemain futsal usia dewasa awal, individu sering mengalami ketegangan emosional. Saat pemain futsal mengalami ketegangan emosi maka pemain futsal tersebut sebgaian besar tidak bisa mengontrol dirinya sendiri. Kontrol diri adalah upaya mengesampingkan atau menghambat reaksi otomatis, kebiasaan, atau perilaku yang dibawa sejak kecil, desakan-desakan, emosi, atau hasrat yang dapat mengganggu pencapaian tujuan utama.Artinya individu kurang bisa mengontrol dirinya tersebut pada saat pertandingan futsal. Sedangkan teamwork adalah bentuk kerja kelompok dengan keterampilan yang saling melengkapi ketika berkomitmen untuk mencapai tujuan bersama secara efektif dan efisien. Penelitian ini bertujuan untuk mengetahui hubungan kontrol diri dengan teamwork pada pemain futsal dewasa awal di Jakarta Timur. Subjek penelitian berjumlah 110 orang dengan menggunakan Accidental Sampling. Metode analisa data menggunakan metode uji korelasi statistik yaitu korelasi product moment. Berdasarkan analisis data ditemukan bahwa terdapat hubungan yang yang signifikan antara kontrol diri dengan teamwork pada pemain futsal usia dewasa awal di Jakarta Timur. Hal ini terlihat dari perolehan angka koefisien korelasinya yang sebesar 0,187 dengan tingkat signifikansi 0,01.
\end{abstract}

Keywords: early adulthood, self-control, teamwork 


\section{PENDAHULUAN}

Setiap orang punya kegemaran, dapat berupa olah raga, seni atau lainnya. Di antara jenis olahraga yang dapat dijadikan hobi di antaranya adalah futsal; hobi yang belakangan ini sangat digemari khususnya oleh kaum laki-laki karena cukup mudah dilakukan. Futsal dapat dilakukan di lapangan yang lebih kecil dari lapangan sepakbola bahkan dapat dilakukan di dalam ruangan . Menurut Justin Lhaksana (2011), futsal adalah olahraga beregu yang membutuhkan kerja sama antar pemain melalui passing yang kuat, bukan sekedar melewati pemain lawan. Kekompakan akan sangat menentukan prestasi, sehingga jumlah goal yang tercetak adalah milik team, tanpa perlu mengidentifikasi siapa pencetaknya.

Pada permainan futsal, seorang pemain yang akan bertanding diharuskan menjunjung tinggi sportifitas dan menaati peraturan yang ditetapkan. Jika ada yang tidak menaati peraturan, tentu akan menimbulkan kerugian bagi tim tersebut, karena tim akan mengalami kesulitan dalam bertanding dan dapat membuat pemain lainnya merasa terbebani (Lhaksana, 2011). Ada fenomena dalam turnamen futsal dimana banyak pemain yang kurang mampu dalam mengontrol diri, contohnya: melakukan pelanggaran, seperti mencederai atau berkata kasar kepada lawan atau secara spontan mengekspresikan kemarahan dengan mengeluarkan kata-kata kasar. Hal-hal tersebut sering ditemukan pada event turnamen futsal antar kampus atau antar SMA, bahkan pada turnamen yang diikuti mahasiswa yang berada pada usia dewasa awal.

Di kalangan pelajar dan mahasiswa, olahraga futsal ini termasuk digemari, sebagai pengganti sepakbola yang membutuhkan lebih banyak pemain dan lebih sulit mengakses lapangannya. Tahap perkembangan mahasiswa berada pada tahap dewasa awal, yaitu kelompok usia hampir dewasa atau baru saja dewasa. Masa dewasa awal merupakan periode penyesuaian diri terhadap pola-pola kehidupan baru dan harapan-harapan sosial baru. Masalah penyesuaian diri menjadikan periode ini suatu periode khusus dan sulit dari rentang hidup seseorang. Fenomena kontrol diri pada mahasiswa menjadi menarik untuk diteliti karena berbeda dengan pelajar yang masih berada pada usia remaja. Pada mahasiswa mereka diharapkan memiliki kematangan emosi sehingga lebih mampu mengontrol dirinya secara lebih baik. Di sisi lain, karena mereka sedang dalam masa peralihan dalam tahapan perkembangan dari remaja ke dewasa, maka mereka mengalami apa yang dinamakan ketegangan emosional. Masa dewasa awal merupakan masa ketegangan emosional dimana jika ketegangan emosi tersebut dapat terus berlanjut sampai usia tiga puluhan. Ketegangan yang dialami umumnya nampak dalam bentuk keresahan. Apa yang diresahkan orang-orang muda itu tergantung dari masalah-masalah penyesuaian diri yang harus dihadapi saat itu dan berhasil tidaknya mereka dalam upaya penyelesaian masalahnya (Hurlock, 1992).

Sebagai olahraga yang dimainkan secara tim, masing-masing individu dalam permainan futsal mempunyai peranan tersendiri bagi tim. Futsal memiliki aturan yang harus ditaati, baik secara individu maupun kelompok. Kesalahan dan pelanggaran yang dilakukan pemain akan diberikan peringatan oleh wasit yang sangat merugikan bagi tim itu sendiri. Oleh sebab itu, pemain harus menunjukkan perilaku yang sportif dalam sebuah pertandingan, serta setiap pemain harus memiliki kontrol diri di dalam maupun luar lapangan agar dapat membantu tim dan tidak merugikan bagi tim itu sendiri. Kontrol diri adalah upaya mengesampingkan atau menghambat reaksi otomatis, kebiasaan, atau perilaku yang dibawa sejak kecil, desakan-desakan, emosi atau hasrat yang dapat mengganggu pencapaian tujuan utama. Kontrol diri ini dilakukan secara sungguh-sungguh termasuk dengan cara mengubah pikiran, perasaan maupun tindakan-tindakan demi pencapaian tujuan besar dan jangka panjang (Muraven \& Baumeister; Muraven, Shmueli dan 
Burkley dalam Ramdhani, Wimbarti dan Susetyo, 2018). Kontrol diri mengacu pada kapasitas untuk mengubah tanggapan sendiri, terutama untuk mengarahkan seseorang sesuai dengan standar seperti cita-cita, nilai-nilai, moral, dan harapan sosial, dan untuk mendukung mereka dalam mengejar tujuan jangka panjang (Baumeister, Vohs \& Tice, 2007).

Menurut Baumeister, Vohs \& Tice (2007), kontrol diri dapat memungkinkan seseorang untuk menahan satu respon atau lebih, dengan demikian mereka bisa memunculkan respon yang berbeda. Tangney, Baumeister \& Boone, A. (2004) menjelaskan bahwa kontrol diri adalah suatu kemampuan untuk mengesampingkan atau mengubah respon di dalam diri seseorang, serta menghilangkan kecenderungan perilaku yang tidak diinginkan dan menahan diri untuk melakukan suatu tindakan. Dengan demikian, pengendalian diri secara garis besar melibatkan suatu kemampuan untuk berubah dan beradaptasi yang baik antara diri sendiri dan dunia

Kontrol diri adalah pengerahan kendali atas diri oleh diri sendiri. Artinya, pengendalian diri terjadi ketika seseorang (atau organisme lain) mencoba untuk mengubah cara dia berpikir, merasa, atau berperilaku (Muraven \& Baumeister, 2000). Kontrol diri adalah fungsi utama dari diri sendiri dan kunci sukses dalam hidup. Pengerahan tenaga dari pengendalian diri tampaknya bergantung pada sumber daya yang terbatas. Hanya saat otot menjadi lelah karena pengerahan tenaga, tindakan pengendalian diri menyebabkan gangguan jangka pendek (penipisan ego) di kemudian hari pengendalian diri, bahkan pada tugas-tugas yang tidak berhubungan. Penelitian memiliki mendukung model kekuatan dalam domain makan, minum, belanja, seksualitas, pemikiran cerdas, membuat pilihan, dan perilaku interpersonal. Motivasi atau faktor pembingkaian dapat memblokir sementara efek yang merusak berada dalam keadaan penipisan ego. Glukosa darah merupakan komponen penting dari energi (Baumeister, Vohs \& Tice, 2007).

Terdapat lima dimensi kontrol diri (Tangney, Baumeister \& Boone, 2004), yaitu:

a. Disiplin diri (self-discipline)

Disiplin diri yaitu mengacu pada kemampuan individu dalam melakukan disiplin diri, seperti tindakan mengikuti peraturan yang ada di lingkungan sosialnya.

b. Tindakan atau aksi yang impulsif (Deliberate/Non-impulsive)

Menilai tentang kecenderungan individu untuk melakukan tindakan yang tidak impulsif (memberikan respon kepada stimulus dengan pemikiran yang matang).

c. Kebiasaan baik (Healthy habits)

Kebiasaan baik merupakan kemampuan individu dalam mengatur pola perilaku menjadi sebuah kebiasaan yang pada akhirnya menyehatkan. Biasanya individu yang memiliki kebiasaan baik akan menolak sesuatu yang dapat menimbulkan dampak buruk walaupun hal tersebut menyenangkan baginya.

d. Etika kerja

Etika kerja berkaitan dengan penilaian individu terhadap regulasi dirinya dalam layanan etika kerja. Biasanya individu mampu memberikan perhatian penuh pada pekerjaan yang dilakukan. Kemampuan mengatur diri individu tersebut di dalam layanan etika.

e. Keterandalan atau keajegan (Realibility) 
Keterandalan atau keajegan merupakan dimensi yang terkait dengan penilaian individu terhadap kemampuan dirinya dalam pelaksanaan rancangan jangka panjang untuk pencapaian tertentu. Biasanya individu secara konsisten akan mengatur perilaku untuk mewujudkan setiap perencanaannya.

Disamping kontrol diri, kerjasama tim juga memainkan peranan besar dalam kesuksesan bermain futsal. Kerjasama tim atau teamwork merupakan bentuk kerja kelompok dengan keterampilan yang saling melengkapi serta berkomitmen untuk mencapai target yang sudah disepakati sebelumnya untuk mencapai tujuan bersama secara efektif dan efisien. Harus disadari bahwa teamwork merupakan peleburan berbagai pribadi yang menjadi satu pribadi untuk mencaopai tujuan bersama. Tujuan tersebut bukanlah tujuan pribadi, bukan tujuan ketua tim, bukan pula tujuan dari pribadi yang paling popular di tim (West, 2012). Teamwork bisa diartikan kerja tim atau kerjasama, teamwork atau kerjasama tim merupakan bentuk kerja kelompok dengan keterampilan yang saling melengkapi ketika berkomitmen untuk mencapai tujuan bersama secara efektif dan efisien. Harus disadari bahwa teamwork merupakan peleburan berbagai pribadi menjadi satu pribadi untuk mencapai tujuan bersama. Tujuan tersebut bukanlah tujuan pribadi, bukan tujuan ketua tim, bukan pula tujuan dari pribadi yang paling popular di tim (West, 2012).

\section{Pengukuran Teamwork}

Dalam penelitian ini, pengukuran teamwork menggunakan lima dimensi teamwork dari Michael A. West (2012) yaitu:

1. Dimensi Personal

a. Tim yang efektif memiliki komitmen yang dalam antara satu dengan yang lain.

b. Segenap tim saling menularkan anthusiasme.

c. Setiap individu memberi kontribusi demi mencapai tujuan bersama.

2. Dimensi Relational

a. Tim yang efektif berkomunikasi secara terbuka dan jujur.

b. Mereka berkolaborasi dengan kesediaan untuk saling melengkapi demi mencapai tujuan bersama.

c. Mereka memanage konflik secara bijak.

3. Dimensi Strategis

a. Tim yang efektif fokus kepada visi yang menjadi pendorong untuk terus maju bersama.

b. Mereka menyepakati dan mengikuti sasaran yang jelas.

\section{Dimensi Proses}

a. Tim yang efektif sangat terbuka terhadap perubahan.

b. Mereka memiliki kesadaran yang kuat akan keterkaitan segenap anggota tim.

Setiap pemain atau individu dalam olahraga futsal memiliki peran masing-masing dalam tim. Mereka yang terlibat harus memiliki komitmen, anthusiasme serta kontribusi demi mencapai tujuan bersama. Dalam tim setiap individu juga harus dapat berkomunikasi secara terbuka dan jujur serta kesediaan untuk saling melengkapi demi menapai tujuan tersebut. Sebagai pemain atau individu yang bekerja atau berinteraksi dalam tim tersebut, indivdu harus memiliki sikap disiplin 
diri, kebiasaan baik, etika kerja, keterandalan, aspek-aspek tersebut tentu sangat mendukung dalam proses tercapainya tujuan bersama. Dalam tim tentunya antar individu diharapkan dapat mengontrol dirinya agar dapat lebih mudah untuk mencapai tujuan bersama yang telah ditentukan dalam tim tersebut. Untuk mencapai tujuan bersama tersebut, setiap pemain atau individu juga yang bekerja sama dalam tim perlu memiliki sikap komitmen, antusiasme dan kontribusi anatar anggota tim. Dalam tim setiap individu juga harus mampu berkomunikasi secara terbuka dan jujur, serta sesama anggota tim mereka diharapkan dapat berkolaborasi dengan kesediaan untuk saling melengkapi demi mencapai tujuan bersama. Jika hal-hal tersebut dimiliki oleh setiap individu maka akan meminimalisir konflik antar sesama pemain atau atau konflik dengan lawan.

Berdasarkan tinjauan teori di atas peneliti membangun asumsi bahwa ada hubungan atau saling keterkaitan antara kontrol diri dengan teamwork. Hipotesa Penelitian sebagai berikut: "Ada hubungan antara Kontrol Diri Dengan Teamwork Pada Pemain Futsal Usia Dewasa Awal di Jakarta Timur". Kerangka penelitian dapat dilihat pada Gambar 1.

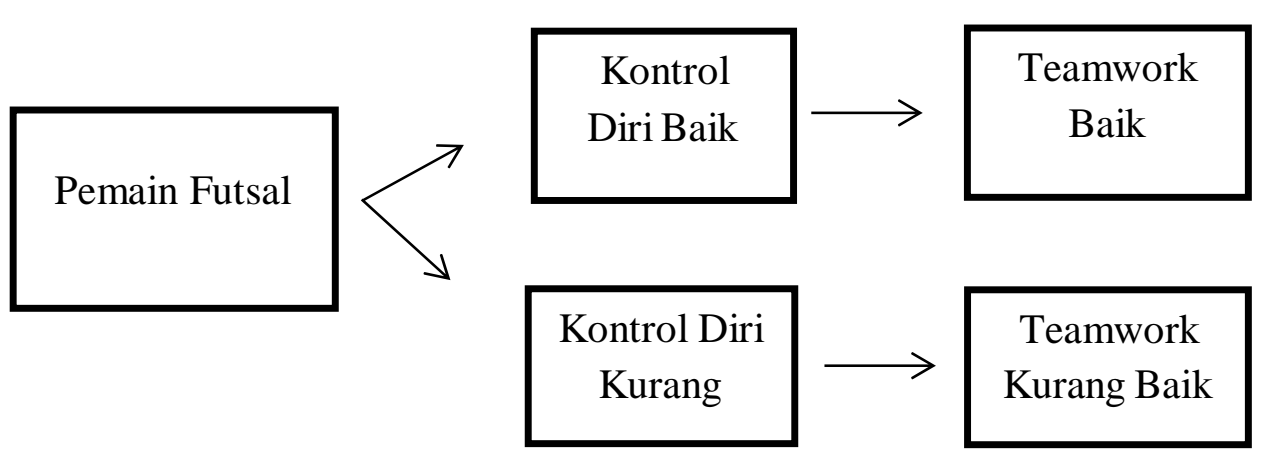

Gambar 1: Kerangka berpikir hubungan antara kontrol diri dengan teamwork

\section{METODE PENELITIAN}

Penelitian ini menggunakan pendekatan kuantitatif korelasional, yang menguji hubungan antara Kontrol diri dengan Teamwork. Sedangkan pengumpulan data menggunakan metode angket (kuesioner), model skala Likert. Penelitian dilakukan kepada populasi dengan batasan sebagai berikut:

- Pemain futsal yang pernah mengikuti turnamen

- Laki-laki

- Berada pada usia dewasa awal (18-40 tahun)

Sample penelitian berjumlah 110 orang, merujuk pada table ukuran sampel Krejcie dan Morgan. Pengambilan sampel menggunakan teknik simple random sampling atau accidental Sampling. Menurut Sugiyono (2010), Accidental Sampling adalah teknik penentuan sampel berdasarkan kebetulan, yaitu sampel yang secara kebetulan bertemu dengan peneliti dapat digunakan sebagai sampel bila dilihat orang yang kebetulan ditemui itu memenuhi syarat sebagai sumber data. Pengambilan anggota sampel dari populasi dilakukan secara acak tanpa memperhatikan strata yang ada di dalam populasi itu. Instrumen penelitian adalah suatu alat yang 
digunakan mengukur fenomena alam maupun sosial yang diamati (Sugiyono, 2010). Instrumen penelitian yang digunakan adalah kuesioner (angket) dengan skala modifikasi model Likert. Pilihan terdiri dari empat alternatif jawaban, yaitu: SS (sangat setuju). S (setuju), TS (tidak setuju), STS (sangat tidak setuju). Masing-masing pernyataan yang ada dalam kuesioner tersebut mempunyai skala satu sampai empat.

\section{Validitas \& Realiabilitas Alat Ukur}

\section{Uji Validitas Skala Kontrol Diri}

Skala kontrol diri diujikan secara langsung kepada subjek penelitian yang berjumlah 110 orang pemain futsal di Jakarta Timur. Kaidah perhitungan Validitas item mengacu pada $\mathrm{r}$ table, dimana batas $\mathrm{r}$ yang dipakai sebesar 0,05 (5\%) dengan jumlah sampel sebanyak 110 orang $(\mathrm{N}=110)$. Dengan nilai r product moment sebesar 0,187 , maka bila nilai $\mathrm{r}$-hitung $>\mathrm{r}$-table berarti suatu item dinyatakan valid dan apabila $r$-hitung < r-table berarti suatu item dinyatakan tidak valid. Skala kontrol diri terdiri dari 46 item. Setelah diuji validitas dengan menggunakan rumus Pearson Product Moment diperoleh 42 item yang valid dengan batas nilai $\mathrm{r}$ hitung $>0,187$ dan 4 item sisanya masuk dalam kategori tidak valid atau gugur dengan batas nilai $\mathrm{r}$ hitung $<0,187$.

\section{Uji Reliabilitas Skala Kontrol Diri}

Reliabilitas adalah sejauh mana hasil suatu pengukuran dapat dipercaya, dalam pelaksanaan pengukuran terhadap subjek yang sama diperoleh hasil yang relatif sama. Untuk menguji reliabilitas alat ukur dilakukan dengan menggunakan teknik pengukuran Alpha Cronbach.

Table 1: Hasil Uji Reabilitas Skala Kontrol Diri

\begin{tabular}{|l|l|l|l|}
\hline Dimensi & Reliabilitas & $\begin{array}{l}\text { Jumlah } \\
\text { Item }\end{array}$ & Keterangan \\
\hline Kontrol Diri & 0,886 & 42 & Reliabel \\
\hline
\end{tabular}

Table 2: Hasil Perhitungan dengan SPSS Uji Reabilitas Skala Kontrol Diri

\section{Reliability Statistics}

\begin{tabular}{|c|r|}
\hline $\begin{array}{l}\text { Cronbach's } \\
\text { Alpha }\end{array}$ & N of Items \\
\hline .886 & 42 \\
\hline
\end{tabular}

Dari hasil uji reliabilitas diperoleh koefisien $(\alpha)$ untuk skala kontrol diri adalah sebesar 0,886 dari empat puluh dua item. Hasil pengujian tersebut menunjukkan koefisien yang reliabel karena koefisien reliabilitas $(\alpha)$ memiliki nilai $>$ r-tabel yaitu 0,187 . Artinya dari 42 item yang terdapat pada skala ini sudah konsisten (lihat table 1 dan 2). 


\section{Uji Validitas Skala Teamwork}

Skala Teamwork diujikan kepada subjek penelitian yang berjumlah 110 orang pemain futsal di Jakarta Timur. Perhitungan validitas item mengacu pada r-table, dimana batas $\mathrm{r}$ yang dipakai dengan taraf signinfikan sebesar $0,05(5 \%)$ dan banyaknya sampel berjumlah 110 orang $(\mathrm{N}=110)$ dengan demikian $\mathrm{r}$-tabel sebesar 0,187 . Sehingga apabila nilai $r$-hitung $>\mathrm{r}$ table berarti suatu item dinyatakan valid dan apabila r-hitung < r-table berarti suatu item dinyatakan tidak valid. Skala teamwork terdiri dari 54 item. Setelah diuji validitas dengan menggunakan rumus Pearson Product Moment, maka diperoleh 50 item yang valid dengan batas nilai r-hitung > 0,187 dengan $\mathrm{N}=110$, dan 4 item sisanya masuk dalam kategori tidak valid atau gugur dengan batas nilai $\mathrm{r}$-hitung $<0,187$.

\section{Uji Reliabilitas Skala Teamwork}

Dari hasil pengujian reliabilitas skala teamwork diperoleh koefisien reliabilitas $(\alpha)$ untuk skala Teamwork adalah sebesar 0,903 dari lima puluh item. Hasil pengujian tersebut menunjukkan koefisien yang reliabel karena koefisien reliabilitas $(\alpha)$ memiliki nilai $>$ r-tabel yaitu 0,187 . Artinya dari lima puluh item yang terdapat pada skala ini sudah konsisten (lihat table 3 dan 4 )..

Table 3: Hasil Uji Reabilitas Skala Teamwork

\begin{tabular}{|l|c|c|c|}
\hline \multicolumn{1}{|c|}{ Dimensi } & Reliabilitas & Jumlah Item & Keterangan \\
\hline Teamwork & 0,903 & 50 & Reliabel \\
\hline
\end{tabular}

Table 4: Hasil Perhitungan dengan SPSS Uji Reabilitas Skala Teamwork

Reliability Statistics

\begin{tabular}{|r|r|}
\hline $\begin{array}{c}\text { Cronbach's } \\
\text { Alpha }\end{array}$ & N of Items \\
\hline .903 & 50 \\
\hline
\end{tabular}




\section{Metode Analisis Data}

Metode analisis data dalam penelitian ini didasarkan atas tujuan hipotesis penelitian, yaitu untuk mengetahui hubungan Kontrol diri dengan Teamwork pada pemain futsal usia dewasa awal di Jakarta Timur. Uji korelasi statistik yang digunakan adalah korelasi product moment. Teknik ini digunakan karena kedua jenis data yang akan dikorelasikan berbentuk ordinal. Dalam pengerjaannya, uji korelasi akan dilakukan dengan bantuan program computer SPSS 21. Adapun rumus korelasi product moment adalah sebagai berikut:

$$
r_{x y}=\frac{N \sum X Y-\left(\sum X\right)\left(\sum Y\right)}{\sqrt{\left\{N \sum X^{2}-\left(\sum X\right)^{2}\right\}\left\{N \sum Y^{2}-\left(\sum Y\right)^{2}\right\}}}
$$

Keterangan:

r: Koefisien korelasi antar skor butir dengan skor total

n: Jumlah responden

$\mathrm{X}$ : Skor butir pada nomor butir ke-i

Y: Skor total responden

Hubungan dua variabel atau lebih dikatakan positif bila nilai satu variable ditingkatkan, maka akan meningkatkan variable yang lain, dan sebaliknya bila nilai satu variabel diturunkan, maka akan menurunkan nilai variabel dikatakan negatif bilai nilai satu variabel ditingkatkan, maka akan menurunkan nilai variabel yang lain. Kuat atau lemahnya hubungan antar variabel dinyatakan dalam koefisien korelasi. Koefisien korelasi terbesar adalah 1 dan koefisien korelasi negatif terkecil adalah -1 , sedangkan yang terkecil adalah 0 . Bila hubungan antar dua variabel atau lebih itu mempunyai koefisien korelasi sebesar 1 atau -1 , maka hubungan tersebut sempurna.

Berdasarkan perhitungan yang dilakukan dengan menggunakan rumus korelasi productmoment, didapat korelasi antara kontrol diri dengan Teamwork sebesar 0,487, pada taraf siginifikansi $0,01(1 \%)$, p value (nilai signifikan) < alpha $(\alpha)$ yaitu $0,01(1 \%)$. Jadi Ho ditolak Ha diterima, artinya ada hubungan yang signifikan antara Kontrol Diri Dengan Teamwork Pada Pemain Futsal Usia Dewasa Awal di Jakarta Timur. Dengan demikian dapat disimpulkan bahwa terdapat hubungan yang signifikan antara Kontrol diri dengan Teamwork. 


\section{HASIL DAN PEMBAHASAN}

Berdasarkan data yang diperoleh dari penelitian, menunjukan bahwa ada hubungan antra kontrol diri dengan teamwork pada pemain futsal usia dewasa awal di jakarta timur semakin tinggi kontrol diri seseorang maka semakin tinggi teamwork, sebaliknya semakin rendah kontrol diri sesorang maka semakin rendah pula teamwork pemain futsal usia dewasa awal di jakarta timur. Teamwork tidak dapat dilepaskan dari kemampuan pemain futsal dalam mengontrol diri saat bertanding di lapangan. Untuk dapat menghasilkan teamwork yang baik maka dibutuhkan perilaku disiplin diri, kebiasaan baik serta etika kerja. Ketika pemain futsal melakukan suatu pertandingan dan berhadapan dengan lawan main maka individu tersebut harus memiliki etika kerja dan kebiasaan baik serta mampu mendisiplinkan dirinya. Untuk dapat membangun teamwork yang baik, pemain futsal juga harus memiliki sikap atau perilaku seperti komitmen, antusiasme, dan kontribusi antar anggota tim demi mencapai tujuan bersama. Pemain futsal juga harus memiliki sikap yang terbuka dan jujur agar mereka dapat memanage konflik secara bijak.

Tabel 5. Korelasi Dimensi Kontrol diri dengan Teamwork

\begin{tabular}{|l|c|}
\hline \multicolumn{1}{|c|}{ Dimensi Kontrol Diri } & Korelasi \\
\hline Disiplin Diri & 0,458 \\
\hline Tindakan yang impulsive & 0,541 \\
\hline Kebiasaan Baik & 0,467 \\
\hline Etika Kerja & 0,387 \\
\hline Keterandalan & 0,389 \\
\hline
\end{tabular}

Berdasarkan perhitungan korelasi masing-masing dimensi kontrol diri dengan teamwork didapatkan hasil sebagai berikut: tindakan yang impulsif memiliki korelasi yang paling tinggi dengan teamwork dibandingkan dengan dimensi lainnya. Ini menunjukkan bahwa kebiasaan baik lebih mampu membantu pemain futsal usia dewasa awal untuk dapat bekerja sama dalam tim. (lihat table 5), Hal ini sesuai dengan pendapat yang dikemukakan oleh Chaplin (2002) Kontrol diri adalah kemampuan individu untuk mengarahkan tingkah lakunya untuk menekan atau menghambat dorongan yang ada. Berdasarkan hasil jawaban responden, pemain futsal yang berusia dewasa awal di Jakarta Timur menjadikan tindakan impulsif sebagai faktor utama dalam mengendalikan diri mereka. Mereka selalu bertindak berdasarkan stimulus yang mereka terima.

Dimensi berikutnya yaitu kebiasaan baik juga berkorelasi dengan teamwork. Sesuai dengan yang dikemukakan oleh Muraven, M \& Baumeister, R. (2000), bahwa kontrol diri adalah upaya mengesampingkan atau menghambat reaksi otomatis, kebiasaan, atau perilaku yang dibawa sejak kecil, desakan-desakan, emosi dan hasrat yang dapat mengganggu pencapaian tujuan utama. Kontrol diri dilakukan secara sungguh-sungguh dengan cara mengubah pikiran perasaan, maupun tindakan-tindakan demi pencapaian tujuan besar dan jangka panjang.

Berdasarkan data diatas, dapat dikatakan bahwa pemain futsal usia dewasa awal yang mempunyai kontrol diri yang baik, akan akan mampu membangun teamwork yang baik, karena mereka selalu dapat mengontrol dirinya atas stimulus yang mereka terima. Sebaliknya pemain futsal yang kontrol dirinya rendah, kurang mampu membangun teamwork yang baik, karena 
mereka tidak bisa mengontrol dirinya atas stimulus yang diterima dan mereka bertindak sesuai kebiasaan sehari-hari mereka.

\section{KESIMPULAN DAN SARAN}

Berdasarkan hasil penelitian, maka dapat disimpulkan bahwa ada hubungan yang signifikan antara kontrol diri dengan teamwork pada pemain futsal usia dewasa awal di Jakarta Timur. Dengan demikian, bagi yang ingin meneliti lebih lanjut mengenai variable yang sama, penelitian ini dapat dijadikan sebagai referensi. Penelitian ini juga dapat diperluas ke bidangbidang lain yang membutuhkan kontrol diri dan kerjasama dengan populasi yang berbeda. Dalam kegiatan di lapangan, kepada pemain futsal perlu diberikan pelatihan kontrol diri agar mereka dapat meningkatkan aspek-aspek control dirinya sehingga saat bertanding, akan dapat memberikan kontribusi yang baik bagi team.

\section{DAFTAR PUSTAKA}

\section{Book in print}

Calhoun, J.F \& Accocela J.R (1990), Psikologi Tentang Penyesuaian Dan Kemanusiaan. Semarang: IKIP Press.

Chaplin, J.P (2002). Kamus Lengkap Psikologi. Jakarta: Rajawali Press.

Daft, R.L. (2006). Era Baru Manajemen, Jakarta: Salemba Empat.

Hariandja, M.T.E. (2007). Manajemen Sumber Daya Manusia, Jakarta: PT.Grasindo.

Hurlock, E.B (1992) Psikologi perkembangan: suatu pendekatan sepanjang rentang kehidupan. Edisi ke 5 (terjemahan). Jakarta: Penerbit Erlangga.

Lazarus, R.S (2010). Psikologi Pendidikan Berbasis Analisis Empiris Aplikatif, Jakarta: Kencana Prenadia Media Grup.

Lhaksana, J. (2011). Taktik dan Strategi Futsal Modern, Jakarta: Be Champion.

Murhananto, (2006). Dasar-dasar Permainan Futsal, Jakarta: Kawan Pustaka.

Ramdhani, N. (2018) Psikologi Untuk Indonesia Tangguh dan Bahagia, Yogyakarta: Gadjah Mada University Press.

Scheumann, S.T, (2013) 101 Tanya Jawab Seru Tentang Sepak Bola, Jakarta: PT Gramedia Pustaka Utama.

Soekanto, S 2004 Psikologi Keperawatan, Jakarta: Penerbit Buku Kedokteran. 
Tracy, B. (2006). Pemimpin Sukses, Cetakan Keenam, Penerjemah: Suharsono dan Ana Budi Kuswandani, Jakarta: Pustaka Delapatrasa.

West, M.A. (2012). Effective Teamwork: Practical Lessons from Organizational Research, 3rd Edition, UK: Wiley-Blackwell.

William, J. 2008. Prinsip-Prinsip Pemasaran, Jakarta: Erlangga.

eJournal (from internet)

Baumeister, Vohs \& Tice. (2007). The Strength Model of Self-Control. Current Directions in Psychological Science. 16. 351-355. 10.1111/j.1467-8721.2007.00534.x.

Muraven, M \& Baumeister, R. (2000). Self-Regulation and Depletion of Limited Resources: Does Self-Control Resemble a Muscle? Psychological bulletin. 126. 247-59. 10.1037/0033- 2909.126.2.247.

Tangney, J. \& Baumeister, R. \& Boone, A. (2004). High Self-Control Predicts Good Adjustment, Less Pathology, Better Grades, and Interpersonal Success. Journal of personality. 72. 271-324. 10.1111/j.0022-3506.2004.00263.x.

DOI : $\underline{\text { https://doi.org/10.31479/intensi.v1i1.3 }}$ 